\title{
Rectangular array current transducer with integrated microfluxgate sensors
}

\author{
Andrey Chirtsov ${ }^{1}$, Pavel Ripka ${ }^{1}$, Jan Vyhnánek ${ }^{1}$ \\ ${ }^{1}$ Department of Measurement, Faculty of ElectricalEngineering, Czech Technical University in Prague, Prague, Czech Republic \\ chirtand@fel.cvut.cz, ripka@ fel.cvut.cz, vyhnajan @fel.cvut.cz
}

\begin{abstract}
Novel rectangular yokeless cu rrent tran sducer with the range $400 \mathrm{~A}$ using 16 microfluxgate sensors around the busbar conductor is presented in this paper. Compared to yokeless transducers u tilizing the differen tial pair of magnetic sensors, our solution has much better suppression of external currents (lower crosstalk). Compared to indu strial transducers with yoke, the new transducer has 10-times lower noise, 10-times be tter temperature stability, and same crosstalk. Sens or design, different methods for calculating the current and temperature dependence are presented in this paper. Crosstalk error is examined in dependence on the number of the operating sensors and external current position.
\end{abstract}

Keywords-current sensor; microfluxgate sensors; rectangular sensor array, Finite element modelling;

\section{INTRODUCTION}

Contactless transducers that measure the electric current usually have a magnetic yoke around the current conductor. The purpose of the yoke is to concentrate the magnetic flux inside this yoke because of its small reluctance [1].

This method has definite advantages - the measurement does not depend on the position of the current conductor in side the yoke, and shields against the external magnetic fields. Hall sensors are dominant sensors that are used in connection with the magnetic yoke, but they can significantly affect the measurement accuracy such as temperature stability of the offset, gain, noise, and non-linear effects. The influence of these factors can be reduced by using a microsystem with continuous sensitivity calibration (achievable drift below 80 $\mathrm{ppm} /{ }^{\circ} \mathrm{C}$ and nonlinearity is less than $\pm 0.08 \%$ ) [2]. On the other hand, transducers with magnetic yoke has several dis advantages such as the size of the transducer since the sensor requires the sizable magnetic core, nonlinear effects of the magnetic material of the yoke due to the saturation and hysteresis of the core and the impossibility of using more precise magnetic sensors due to the concentrated magnetic field. Another approach for meas uring current are the sensors without yoke. The first type of yokeless currents sensor uses hole drilled in the middle of the busbar with inserted 2 microfluxg ate sensors located on opposite sides of the PCB [3]. This setup allows us to measure cument with the range $\pm 500 \mathrm{~A}$ and with linearity error lowerthan $0.1 \%$. The advantage of this solution is simplicity, low-power consumption and low-cost. The disadvantage of this method is mainly crosstalk effect which can be eliminated by using a configuration with $3 \mathrm{x}, 4 \mathrm{x}$ or $6 \mathrm{x}$ microfluxgate sensors [4] and need for the drilling hole in the middle of the busbar. The other problem is frequency dependence due to non-uniform current distribution caused by eddy currents in the solid bar. In [5] and
[6] a busbar with an amphitheater hole and wedge bar respectively is shown, these methods significantly reduce frequency dependence. A similar busbarsensor with a range of $300 \mathrm{~A}$ is described in [7]. It uses an AMR sensor bridge in a semi-cylindricals lot in the busbar. Circular sensor array is also a common method of measurement providing less dependence of reading on the conductor position and better crossfield immunity [8]. This approach was recently used in [9] using microfluxgate sensors. The disadvantage of circular array is that the size of the transducer is impractical and makes its installation inaccessible in hard-to-reach places. Measuring setup with AMR sensors is also possible but this has insufficient range ( $\pm 8 \mathrm{~A}$ ) due to the AMR sensor field range of $200 \mathrm{uT}$. [10].

\section{YOKELESS CURRENT SENSOR DESIGN}

In this paper, we suggest a new method for measuring the current flowing through the busbar without the yoke; instead the closed loop is approximated by 16 integrated microfluxgate sensors TI DRV425 placed on the circumference of the conductor. The sensor is designed for the maximum current of 400 A. Fluxgate sensors are much more sensitive than Hall sensors, and they have advantages over almost all characteristics such as temperature stability, noise and, nonlinearity. The disadvantage is the relatively small full range with the comparison with Hall sensor which is $2 \mathrm{mT}$. The current transducer is designed to meas ure current in aluminum busbar conductor with the cross-section of $100 \times 10 \mathrm{~mm}$ which is commonly used as the ground conductor in power stations as shown in Fig. 1. Using the current transducers on the iron introduce the additional errors and should be recalibrated due to the busbar permeability [11].

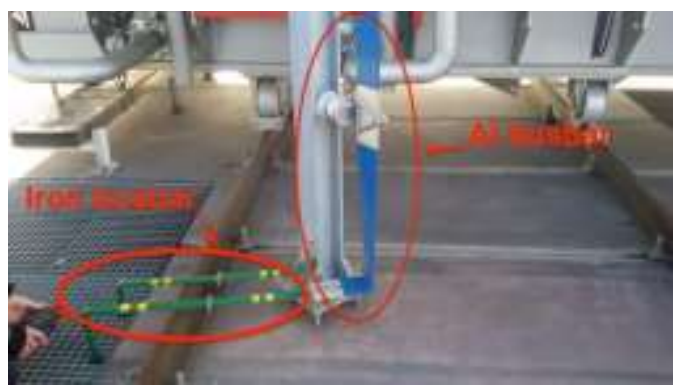

Figure 1: $\mathrm{Al}$ and Iron busbar as a ground conductor at the power station in the Czech Republic

The sensor has dimensions of 104x14 mm which makes it very compact and easy to install. Each microsensor is individually feedback compensated, and all necessary electronics is integrated inside the sensor chips, the only adjustable extemal 
Chirtsov, A.; Ripka, P.; Vyhnánek, J.: Rectangular Array Current Transducer with Integrated microfluxgate Sensors In: Proceeding - 2018 IEEE SENSORS. IEEE SENSORS, 2018. ISBN 978-1-5386-4707-3.

component is a shunt resistor. Full-scale (FS) range of the microsens or and, therefore, the current transducer can be adjusted using the shunt resistor. Utilizing such a number of operating sensors can significantly reduce the influence of the external magnetic fields including those caused by external currents by better approximation of the closed line integral in the Ampere's law. Finite element modeling is performed for design parameters of the sensor and the verification of the measurements. In further, FEM can be used to optimize the location and number of magnetic sensors to achieve desired precision and crosstalk error. The experimental model of the sensor is shown in Fig. 2. Commercially available LEM sensor HOP 800-SB is used to compare the properties of the yokeless current transducer. The LEM sen sor consists of 2 Hall sensors, magnetic core and operates without feedback compensation. The distance between the particular integrated fluxgate sensors DRV425 is $14 \mathrm{~mm}$, and the distance between the sensors and the surface of the busbar is $3.5 \mathrm{~mm}$. Distribution of the microfluxg ate sensors around the busbar is shown in Fig. 3. The sensor outputs are read by the NI-DAQ card and processed by the software.

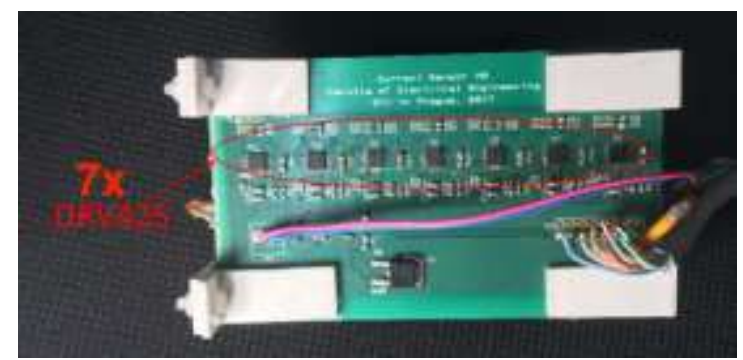

Figure 2: Picture of the yokeless current transducer with the 16 integrated microfluxgate sensors

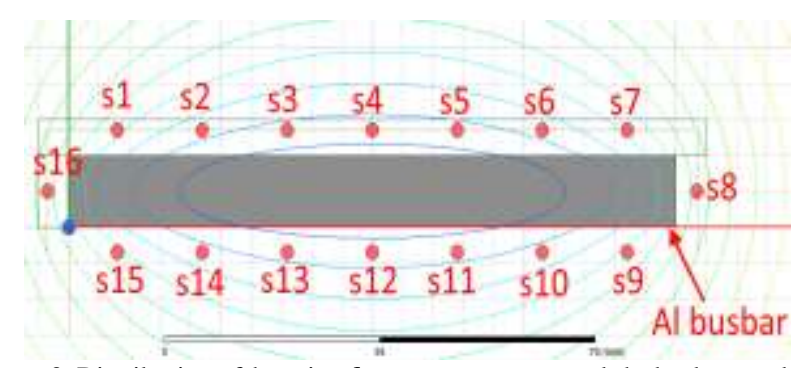

Figure 3: Distribution of the microfluxgate sensors around the busbar conductor

\section{CAlCUlATING WEIGHTS COEFFICIENTS FOR EACH SENSOR}

Each sensor should have individual weight for correct computation of the current. FEM simulation is performed to find the weights. For the material properties are the following parameters: for the aluminum relative permeability $\mu=1.000021$ and conductivity $\mathrm{S}=31.713 \mathrm{e}^{6} \mathrm{~S} / \mathrm{m}$. The electrical conductivity of the Albusbar was measured using 4 - terminal method with the measuring current of $50.25 \mathrm{~A}$ in the region of the homogenous current density. Three different methods of calculating the weight are used for each sensor. The sumof the sensor output signals is an approximation of the Ampere's magnetic field circulation.

\section{A. Same weights}

All particular sensors have the same weight w (A/ (A/m)). Current is calculated by (2). For DC current calculated weight is $w_{i}=0.0147$, where $w_{i}$ is the individual weight and $H_{i}$ is the measured strength of the magnetic field for the i-th microfluxgate sensor. This method is the simplestone and does not require a lot of resources in the calculation of the current.

$$
\begin{gathered}
w=w_{1}=w_{2}=w_{3}=\cdots=w_{16} \\
I_{\text {measured }}=w\left(H_{1}+H_{2}+H_{3}+\cdots+H_{16}\right)
\end{gathered}
$$

\section{B. Integralmethod}

The surface of the whole busbar is divided into separate regions corresponding to each of 16 sensors. These lines show the tangential component of the magnetic field strength at a distance of $3.5 \mathrm{~mm}$ from the edge of the busbar. For calculating the weights for each sensor, the line corresponding to thesensor is numerically integrated and divided by the theoretical value of the magnetic field strength obtained by FEM in the site of this sensor.

$$
\begin{gathered}
w_{i}=\frac{\int H_{t_{i}} d l}{H_{F E M} i} \\
I_{\text {measured }}=\left(w_{1} H_{1}+w_{2} H_{2}+w_{3} H_{3}+\cdots+w_{16} H_{16}\right)
\end{gathered}
$$

This coefficient should be calculated for each sensor separately, but these weights are symmetrical with respect to the center of the busbar. Total current is calculated by the (4).

\section{Weightedmethod}

The weight for each sensor was obtained by dividing the known applied current in simulation flowing the busbar by the theoretical value of the tangential magnetic field strength in the site of the sensor. The equation for calculating the weights for each sensor and the total current is shown in (5), (6), respectively.

$$
\begin{aligned}
w_{i} & =\frac{I_{\text {total }}^{\text {simulation }}}{H_{F E M i}} \\
I_{\text {measured }}= & =\frac{w_{1} H_{1}+w_{2} H_{2}+w_{3} H_{3}+\cdots+w_{16} H_{16}}{16}
\end{aligned}
$$

\section{CHARACTERISTICS OF THE YOKELESS TRANSDUCER} AND LEM SENSOR

\section{A. Offset stabilitywithtemperature}

Offset drift was tested only for three different temperatures. Results of the offset value for LEM and yokeless transducer for the various current calculation methods are shown in Table 1 and 2 , respectively. The estimated values for the temperature drift are shown in Table 3.

TABLE I. MEASURED OFFSET VALUE AT DIFFERENT TEMPERATURES FOR LEM HOP 800-SB

\begin{tabular}{|c|c|}
\hline Temperature $\left({ }^{\circ} \mathbf{C}\right)$ & Offset $(\mathbf{m A})$ \\
\hline-22.2 & 2850 \\
\hline 25.3 & 840 \\
\hline 59.9 & -1104.9 \\
\hline
\end{tabular}


Chirtsov, A.; Ripka, P.; Vyhnánek, J.: Rectangular Array Current Transducer with Integrated microfluxgate Sensors In: Proceeding - 2018 IEEE SENSORS. IEEE SENSORS, 2018. ISBN 978-1-5386-4707-3.

TABLE II. MEASURED OFSSET VALUES AT DIFFERENT TEMPERATURES FOR YOKELESS TRANSDUCER

\begin{tabular}{|c|c|c|c|}
\hline \multirow{2}{*}{$\begin{array}{c}\text { Temperature } \\
\left({ }^{\circ} \mathbf{C}\right)\end{array}$} & \multicolumn{3}{|c|}{ Offset (mA) } \\
\cline { 2 - 4 } & $\begin{array}{c}\text { Same } \\
\text { weights }\end{array}$ & $\begin{array}{c}\text { Integral } \\
\text { method }\end{array}$ & $\begin{array}{c}\text { Weighted } \\
\text { method }\end{array}$ \\
\hline-11 & -301 & 249 & 389 \\
\hline 25.3 & 220 & 193 & 305 \\
\hline 55 & 99 & 92.24 & 182.4 \\
\hline
\end{tabular}

TABLE III. OFFSET TEMPERATURE DRIFTS CALCULATED FOR LEM AND YOKELESS TRANSDUCER

\begin{tabular}{|l|c|c|c|c|}
\hline Parameters & LEM & \multicolumn{3}{|c|}{ Yokeless transducer } \\
\cline { 3 - 5 } & HOP & $\begin{array}{l}\text { Same } \\
\text { 800-SB }\end{array}$ & $\begin{array}{l}\text { Integral } \\
\text { weights }\end{array}$ & $\begin{array}{l}\text { Weighted } \\
\text { method }\end{array}$ \\
\hline FS range & 800 & \multicolumn{3}{|c|}{400} \\
\hline Drift $\left(\mathrm{mA} /{ }^{\circ} \mathrm{C}\right)$ & 48.1 & 3.06 & 3.13 & 2.37 \\
\hline $\begin{array}{l}\text { Drift } \\
\left(\% \mathrm{FS} /{ }^{\circ} \mathrm{C}\right)\end{array}$ & $6 \mathrm{e}-3$ & $7.65 \mathrm{e}-4$ & $7.83 \mathrm{e}-4$ & $5.93 \mathrm{e}-4$ \\
\hline
\end{tabular}

\section{B. Noise}

The noise analysis for LEM sensor is performed by FFT Analyzer SR770, and for theyokeless sensor the nois e spectrum is calculated using the software. The measured power spectral density (PSD) for LEM sensor @ $1 \mathrm{~Hz}$ is 45.7 $\mathrm{mArms} / \mathrm{sqrt}(\mathrm{Hz})$. For the yokeless sensor, the PSD is affected by two factors - the separate noise of the DAQ card and the sensors thems elves. PSD of the DAQ card itself equals to 1.38 mArms/sqrt(Hz) @1 Hz, while total PSD (DAQ card + 16 sensors) is $2.94 \mathrm{mArms} / \mathrm{sqrt}(\mathrm{Hz})$ @ $1 \mathrm{~Hz}$. We may conclude that the noise of yokeless transducer is much lower compared to the LEM HOP 800-SB.

\section{Crosstalk error of the reading}

External current has the significant influence on the current reading of both sensors. Response to the realistic external DC current $10 \mathrm{~A}$ in the perpendicularplane $90^{\circ}$ and at $45^{\circ}$ direction is measured and shown in Fig. 4 and 5, respectively. The main reas on of the current reading error is the distance to the extemal current and the selected processing method for the yokeless current sensor, the dependence of the Hall sensors displacement of the LEM sensor due to the asymmetric split core. In the minimum realistic distance of $15 \mathrm{~cm}$ in power stations, the enror of yokeless sensor is always below $0.5 \%$, while for the LEM sensor the same error is $1 \%$.

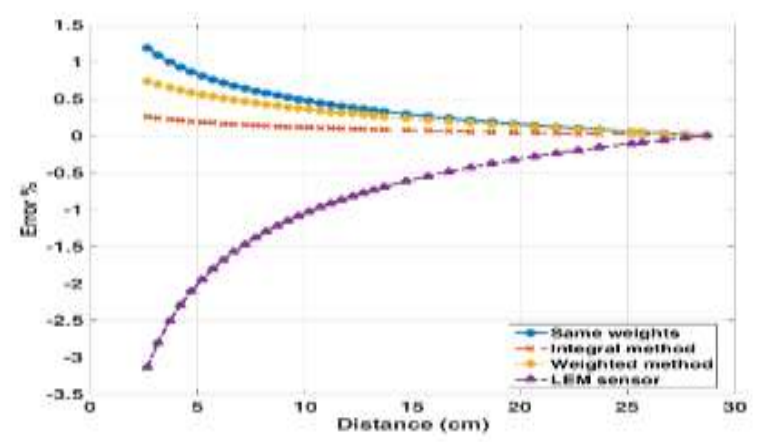

Figure 4: Reading error of the LEM and yokeless sensor: influence of the superior $\left(90^{\circ}\right)$ external $\mathrm{DC}$ current of $10 \mathrm{~A}$ as a function of the distance

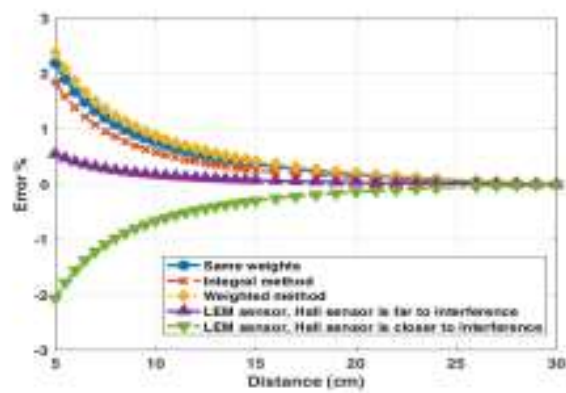

Figure 5: Reading error of the LEM and yokeless sensor: influence of the external DC current of $10 \mathrm{~A}$ as a function of the distance in $45^{\circ}$ position

\section{Reading error in dependence on theoperating sensors}

As mentioned above, the higher number of the integral points reduces the current reading error. Crosstalk error in dependence on the number of operating micros en sors is shown in Fig. 6 for same weights method; for other methods this dependence is identical. The number of the sensors depends on the application as accurately and reliable the current should be measured. The current reading error is lowered since the larger number of the sensors allows us to better approximate the integral with an increase in the number of operating sensors.

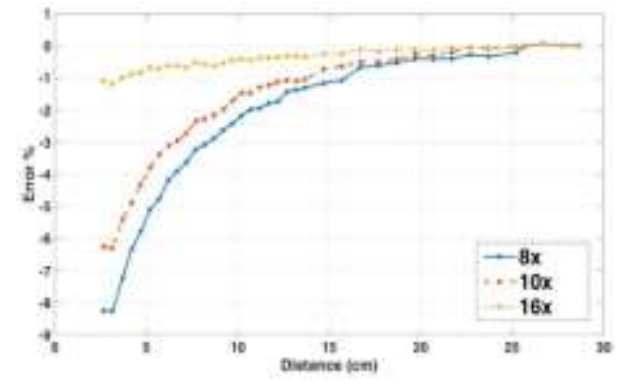

Figure 6: Reading error dependence on the number of the operating sensors, influence of the external DC current in superior position, Same weights method

\section{CONCLUSION}

Current through the busbar can be measured by array of the integrated fluxgate sensors, resolution of $1 \mathrm{~mA}$ is achievable. Placement of sensor array helps to significantly reduce the influence of the crosstalk fields. The maximum measured current for 16 sen sors configuration is $400 \mathrm{~A}$, but this range can be easily changed by increasing the dis tance from the sensor to the busbar. The main advantages of the new method compared to the industry standard are 10-times lower noise, 10-times better temperature stability, more compact size, same low cros stalk error and lower price. The disadvantages of our sensor are the need of DAQ card, digital processing of the output signals, and power consumption of the multi-sensor system Now the current transducers are installed on the neutral line of a dis tribution transformer located in the Czech Republic for the long-term meas urements the geomagnetically induced currents.

\section{ACKNOWLEDGMENT}

This work was supported by the Grant agency of the Czech Republic through the project "New methods for the measurement of electric currents" (GACR 17-19877S). 


\section{Chirtsov, A.; Ripka, P.; Vyhnánek, J.: Rectangular Array Current Transducer with Integrated microfluxgate Sensors}

In: Proceeding - 2018 IEEE SENSORS. IEEE SENSORS, 2018. ISBN 978-1-5386-4707-3.

\section{REFERENCES}

[1] P. Ripka, Electric current sensors: a review, Meas. Science and Technology 21 (2010) Iss. 11, pp.1-23.

[2] Ajbl, A.; Pastre, M.; Kayal, M. A fully integrated Hall sensor microsystem for contactlessw current measurement. IEEE Sensors J. 2013, 13, 22712278, 10.1109/JSEN.2013.2251971

[3] DRV425 Fluxgate Magnetic-Field Sensor, Texas Instruments datasheet at http://www.ti.com/product/DRV425/datasheet

[4] P. Ripka, A. Chirtsov, Busbar current transducer with suppression of external fields and gradienrs, IEEE Transaction on Magnetics, Volume 54, Issue: 11, 2018

[5] A Busbar Current Sensor With Frequency Compensation Pavel Ripka Václav Grim, and Vojtech Petrucha IEEE TRANSACTIONS ON MAGNETICS, VOL. 53, NO. 4, APRIL 2017

[6] P. Ripka, M. Pribil, V. Petrucha, V. Grim, K. Draxler, A Fluxgate current sensor with an Amphitheater Busbar, IEEE Transactions On Magnetics, Vol. 52, Issue 7, July 2016
[7] Z. Zhenhong, O. Syuji, A. Osamu, and K. Hideto, "Development of the highly precise magnetic current sensor module of +/-300 A utilizing AMR element with bias-magnet," IEEE Trans. Magn., vol. 51, no. 1, pp. 1-5, Jan. 2015.

[8] L. Di Rienzo, Z. Zhang, "Spatial harmonic expansion for use with magnetic sensor arrays", IEEE Trans. Magn., vol. 46, no. 1, pp. 53-58, Jan. 2010

[9] Weiss, R., Makuch, R., Itzke, A., \& Weigel, R. Crosstalk in Circular Arrays of Magnetic Sensors for Current Measurement. IEEE Transactions on Industrial Electronics, 2017, 64.6, 4903-4909

[10] Mlejnek, P., Vopálenský, M., Ripka, P. AMR Current Measurement Device. Sensors and Actuators., 2008, 141(1-3), 646-653.

[11] M. Mirzaei, P. Ripka, A. Chirtsov, P. Kaspar, J. Vyhnanek , The effect of conductor permeability on electric current transducers, AIP Advance 8, 047506, 2018 